coagulation factors in reported series (Johnson and Greenwalt, 1965).

The results of coagulation tests in the term neonates were similar to those reported by other writers (Aballi and De Lamerens, 1962; Oski and Naiman, 1966). Whether assessed on gestational age or birth weight, increasing prematurity was accompanied by further impairment of coagulation, particularly in factors V and VII and X complex. One of the most striking aspects of the coagulation status of newborn premature infants was the wide individual variation, so that some had values similar to those of term neonates, whereas others showed varying degrees of coagulation impairment which was sometimes severe. It would seem likely that this wide variation reflects different degrees of hepatic immaturity and not the influence of placental passage of maternal clotting factors.

It has usually been considered that cerebral haemorrhage occurring in low birth weight infants in the first few days of life is primarily due to hypoxic capillary damage. Nevertheless, it seems likely from our results and those reported by Gray et al. (1968) that a severe coagulation deficiency could be a major contributing factor. Thus using the Thrombotest Gray et al. (1968) reported a relationship between cerebral haemorrhage and a coagulation deficiency in low birth weight infants. The results of our detailed coagulation studies have also shown a marked difference in the coagulation status between low birth weight infants who survived and those who died; however, only one-half of the deaths were due to cerebral haemorrhage. This is probably because the coagulation defect is only one manifestation of immaturity and is therefore associated with other complications of marked prematurity. Nevertheless, the coagulation defect was sometimes severe enough to cause haemorrhage in its own right and of ten severe enough to aggravate bleeding produced by trauma or hypoxic capillary damage. A causal relationship between cerebral haemorrhage and a coagulation defect is further supported by the observation that the maximum incidence of cerebral haemorrhage occurs at about the same time as the maximum dip in coagulation factors.

Cerebral haemorrhage is a common cause of mortality in premature infants. Infants at high risk may be detected if screening tests such as the prothrombin and partial thromboplastin times were included in the early assessment of very low birth weight infants. The risk of cerebral haemorrhage might then be significantly reduced if infants shown to have a severe coagulation deficiency were treated prophylactically. Since the coagulation deficiency of prematurity is relatively unresponsive to vitamin $\mathrm{K}$ (Oski and Naiman, 1966), correction of the defect is most readily achieved by administration of small amounts of fresh frozen plasma.

These investigations would not have been possible without the help and co-operation of the medical and nursing staff of $\mathrm{St}$. Vincent's Maternity, the Royal Women's, and the Queen Victoria Hospitals. In particular we would like to thank Dr. W, H. Kitchen and Professor E. C. Wood for their encouragement, and Miss J. Pike for technical assistance. One of us (M. M.) is supported by a grant from the Australian National Heart Foundation. Details of results of individual coagulation tests are obtainable, on request, from Dr. J. Hirsh, to whom all correspondence should be addressed.

\section{REFERENCES}

Aballi, A. J., and De Lamerens, S. (1962). Pediatric Clinics of North America, 9, 785.

Alexander, B., Meyers, L., Kenny, J., Goldstein, R., Gurewich, V., and Grinspoon, L. (1956). New England fournal of Medicine, 254, 358 .

Breton, A., Goudemand, M., Hutin, A., Caudrelier, J.-R, and Gaudier, B. (1960). Archives Françaises dé Pédiatrie, 17, 143.

Fresh, J. W., Ferguson, J. H., and Lewis, J. H. (1956). Obstetrics and Gynecology, 7, 117 .

Gilliland, M. J.' (1966). Minnesota Medicine, 49, 1597.

Gray, O. P., Ackerman, A., and Fraser, A. J. (1968). Lancet, 1, 545.

Hardisty, R. M., and Ingram, G. I. C. (1965). Bleeding Disorders. Oxford, Blackwell.

Hirsh, J., Buchanan, J. G., de Gruchy, G. C., and Baikie, A. G. (1967). Lancet, 1, 418.

Johnson, S. A., and Greenwalt, T. J. (1965). Coagulation and Transfusion in Clinical Medicine. Boston, Little Brown.

Kasper, C. K., Hoag, M. S., Aggeler, P. M., and Stone, S. (1964). Obstetrics and Gynecology, 24, 242.

Kerr, C. B., Preston, A. E., Barr, A., and Biggs, R. (1966). British fournal of Haematology, $12,212$.

Markarian, M., Lindley, A., Jackson, J. J., and Bannon, A. (1967). Thrombosis et Diathesis Haemorrhagica" (Stuttgart), 17, 585.

Oski, F. A., and Naiman, J. L. (1966). Haematologic Problems in the Newborn. Philadelphia, Saunders.

Preston, A. E. (1964). British fournal of Haematology, $10,110$.

Talbert, L. M., and Langdell, R. D. (1964). American fournal of $\mathrm{Ob}$ stetrics and Gynecology, 90, 44.

\title{
Familial Plasma Lecithin:Cholesterol Acyltransferase Deficiency
}

\author{
BENGT HAMNSTRÖM,* M.D.; EGIL GJONE, $†$ M.D. ; KAARE R. NORUM, $\ddagger$ M.D.
}

Summary : A woman with familial plasma lecithin : $\checkmark$ cholesterol acyltransferase (L.C.A.T.) deficiency showed, like the other reported cases, obvious corneal opacity, proteinuria, and moderate anaemia with a slight haemolytic component. In the plasma the concentrations of free cholesterol, triglycerides, and lecithin were high, and those of esterified cholesterol, lysolecithin, and alphalipoprotein were low. L.C.A.T. activity in plasma was $10 \%$ of normal. The heparin-induced lipolytic activity in plasma was reduced. The erythrocyte lipid pattern was abnormal and showed the same pattern as earlier described in L.C.A.T. deficiency.

The patient's brother also probably suffered from the disease and died in uraemia. These are the fourth and fifth known patients with L.C.A.T. deficiency, the first one reported in a male, and the first one with a fatal outcome.

\section{Introduction}

The first three cases of plasma lecithin: cholesterol acyltransferase deficiency (L.C.A.T.) (plasma cholesterol ester deficiency) were reported from Norway (Norum and Gjone, 1967a, 1967b ; Gjone and Norum, 1968a, 1968b). The clinical features include proteinuria, normochromic anaemia with a haemolytic component, corneal opacity (Gjone and Bergaust, 1969), and turbid or milky plasma. Concentrations of plasma total cholesterol, triglycerides, and phospholipids were raised in the two oldest patients, the percentage of esterified cholesterol was very low, and the concentration of lysolecithin distinctly reduced in all cases. As determined by paper electrophoresis, precipitation

* Medical Department, Centrallasarettet, Karlstad, Sweden.

† Medical Department A, Rikshospitalet, University Hospital, Osło, Norway.

$\ddagger$ Institute of Clinical Biochemistry, Rikshospitalet, University of Oslo, Norway. 
with manganese chloride and heparin, and immunoelectrophoresis the concentration of alphalipoproteins was definitely decreased.

Biochemical investigations showed absence of plasma L.C.A.T. Foam cells were found in the bone marrow and in the glomerular tuft of the kidney. Numerous target cells were found, and red cells were shown to have an abnormal lipid pattern (Gjone, Torsvik, and Norum, 1968). Further investigations of the pedigree (Torsvik, Gjone, and Norum, 1968) did not reveal any more cases in this large family. The affected sisters were all adults with few clinical symptoms. All had normal kidney and liver function. We present a Swedish family in which two members have this disorder.

\section{Case 1}

The patient (III 16), a married woman, was born in 1921. Proteinuria was first noted at the age of 3-4 years. In 1945 she had a normal pregnancy with a normal child. In 1949 she was admitted to hospital because of proteinuria, and tonsillectomy was performed. A high antistreptolysin titre was found (6,400 units), the specificity of which could not be determined at that time. Her tonsils were small and adherent. Corneal opacity had been present for as long as she could remember, but was noted in her case notes for the first time in 1955. In March 1967 cholecystectomy was performed because of five pea-sized gallstones that looked like cholesterol stones. The gall bladder wall had signs of slight infection and the liver was distinctly enlarged. Microscopically the liver tissue was described as virtually normal.

The patient had been in hospital several times during the previous years because of diffuse, vague discomforts, most of them probably of a psychogenic origin. Her disease had not been observed to progress during this period. She was of normal physique and intelligence. Liver and spleen were not palpable, but $x$-ray examinations showed very slight enlargement, unchanged during the last years. A needle biopsy of the spleen showed normal cytology. Intravenous pyelography performed in 1960 and in May 1968 showed nothing abnormal. Her corneal opacity was localized in the parenchyma and composed of innumerable minute greyish dots in all layers of the stroma. In the periphery a definite corneal arcus was seen (Fig. 1). Physical examination did not show any abnormalities in the lungs, heart, skin, throat, or nervous system. Blood pressure and electrocardiogram were normal. Gynaecological and rectoscopic examinations were normal. An audiogram showed a moderate hearing defect.

\section{Methods}

Total cholesterol was determined by the method of Carr and Drekter (1956). Total and free cholesterol was estimated according to Babson, Shapiro, and Phillips (1962) or following separation on thin-layer chromatography described by Pié and Giner (1966). Triglyceride analysis was carried out acoording to Laurell (1966) and total phospholipids according to Carlson (1960). Individual phospholipids were measured quantitatively after separation on thin layer chromatography by the method of Gjone and Orning (1966). Plasma L.C.A.T. was determined according to the description of Glosmet and Wright (1964). The acyl groups of the plasma cholesterol esters were determined as described by Norum and Gjone (1967b). Lipoprotein lipase activity in plasma was measured by the method of Boberg and Carlson (1964).

The lipoproteins in plasma were determined in the postabsorptive state. They were separated by paper electrophoresis according to the method of Sonnino and Gazzaniga (1961) with a small modification (adding $0.2 \mathrm{~g}$. of albumin to $1,000 \mathrm{ml}$, of the TEB tris-(hydroxymethyl)-aminomethane, boric acid, and ethylenediaminetetracetic acid) buffer solution), and were stained with Oil Red $O$ according to Jencks and Durrum (1955). The lipoproteins were also separated with the preparative ultracentrifuge according to Bragdon, Havel, and Boyle (1956) and their contents of major lipids were quantitatively measured. To separate the triglyceride-rich lipoproteins the polyvinylpyrrolidone-density gradient method according to Hallberg (1964) was used. (The analyses in the preparative ultraoentrifuge and on the polyvinylpyrrolidone-density gradient were performed by Dr. Jonas Boberg, King Gustaf V Research Institute, Karolinska Sjukhuset, Stockholm.) Alpha-lipoproteins were also measured after precipitation of the beta-lipoproteins with manganese chloride and heparin according to Burstein and Samaille (1960). The lipid pattern of the erythrocytes were estimated according to the description of Gjone et al. (1968).

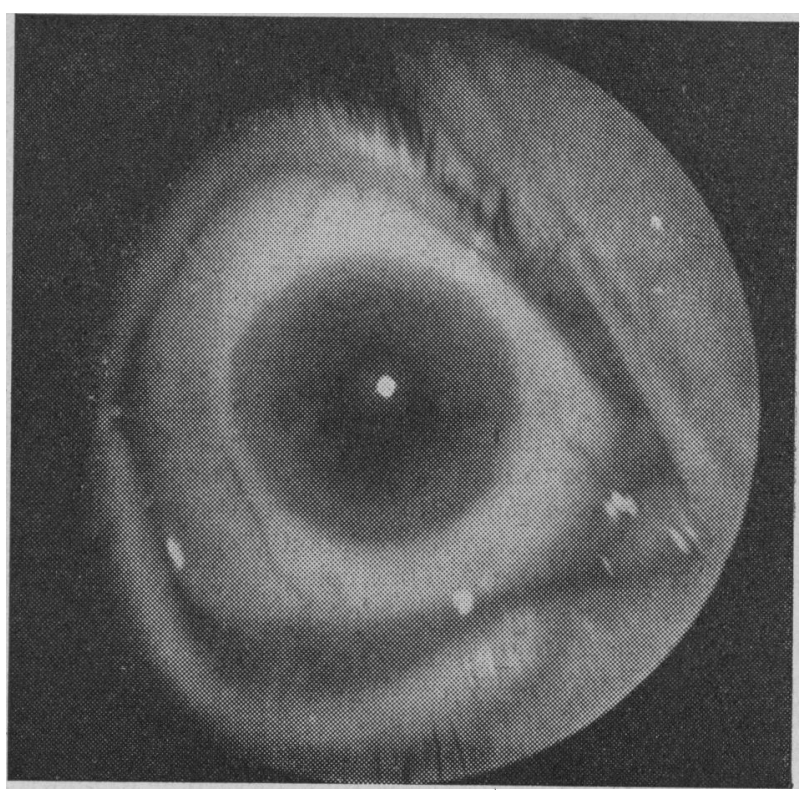

FIG. 1.-Corneal opacity.

\section{Results}

Plasma Lipids.-The fasting values of the major lipid fractions during a normal diet are given in Table $I$. It is seen that triglycerides, total cholesterol, and total phospholipids were all raised. Esterified cholesterol was much below normal, The individual phospholipids showed relatively and absolutely abnormally high becithin and low lysolecithin values (Table I).

TABLE I.-Plasma Lipid Fractions

\begin{tabular}{|c|c|c|c|c|}
\hline & & & Case 1 & Normal Range \\
\hline $\begin{array}{l}\text { Total cholesterol (mg./100 ml.) } \\
\text { Free cholesterol (mg. } / 100 \mathrm{ml} .)\end{array} \quad \ldots$ & 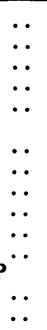 & 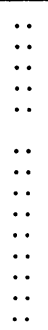 & $\begin{array}{l}369 \\
271 \\
26 \cdot 6 \\
533 \\
380 \\
106 \cdot 1 \\
91 \cdot 09 \\
85 \cdot 9 \\
2 \cdot 17 \\
2 \cdot 0 \\
9 \cdot 32 \\
8 \cdot 8 \\
3 \cdot 52 \\
3 \cdot 3\end{array}$ & $\begin{array}{c}245-326 \\
60-80 \\
10-140 \\
250-300 \\
60 \cdot 3-77 \cdot 2 \\
44 \cdot 0-56 \cdot 0 \\
68 \cdot 6-77 \cdot 5 \\
2 \cdot 6-7 \cdot 2 \\
3 \cdot 7-9 \cdot 3 \\
8 \cdot 2-14 \cdot 9 \\
12 \cdot 6-21 \cdot 8 \\
2 \cdot 1-3 \cdot 5 \\
2 \cdot 9-5 \cdot 6\end{array}$ \\
\hline
\end{tabular}

Plasma L.C.A.T.-The lipid pattern of the plasma (high total cholesterol and lecithin and low esterified cholesterol and lysolecithin) suggested that there was a deficiency in the plasma L.C.A.T. The aotivity of this enzyme was found to be $2 \mathrm{~m} \mu \mathrm{moles} / \mathrm{ml}$./hour. The normal values of this enzyme in our laboratory are in the range of 20 to $30 \mathrm{~m} \mu \mathrm{moles} / \mathrm{ml}$./hour (unpublished observation).

Fatty acid pattern of plasma cholesterol esters.-Patients with familial L.C.A.T. deficiency have an abnormal pattern of plasma cholesterol esters, and the present patient also shows an unusual pattern (Table II), characterized by a relatively high fraction of saturated and monounsaturated acyl groups.

Heparin-induced lipoprotein lipase activity in plasma.-Determinations of lipoprotein lipase activity were made many times under different dietary conditions and were always found to be abnormal. A typical curve in comparison with a normal one is shown in Fig. 2. Inhibitors of the enzyme are not apparently present, because the addition of the patient's plasma to a normal one did not significantly influence the curve. 
TABLE II.-Percentage Distribution of Fatty Acids Esterified with Cholesterol in Plasma from Case 1. Values from Three Norwegian Sisters are Given as Comparisons

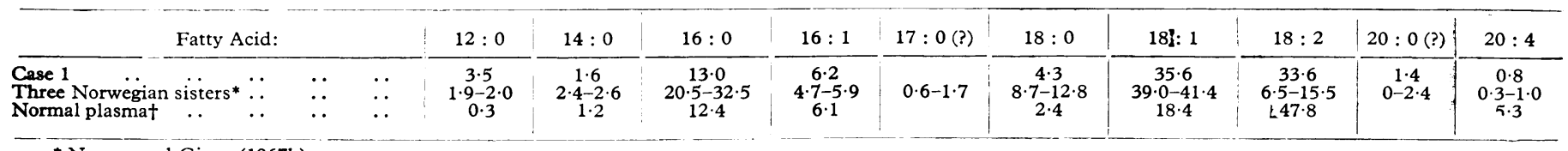

* Norum and Gjone (1967b)

† Schrade, Boehle, Biegler, and Harmuth (1963).

Plasma lipoprotein studies.-No alpha-lipoprotein band could be detected by paper electrophoresis. Only small amounts of alphalipoprotein were found, both with the ultracentrifuge and with the precipitation techniques. No distinct pre-beta-band was seen, and the beta-band was broadened with a definite trail, sometimes accentuated near the starting-point. Much of the triglycerides was located in the top fraction on the polyvinylpyrrolidone-density gradient. The effects of dietary manipulations will be published elsewhere (Hamnström, 1969). The results of determinations with the ultracentrifuge and on the polyvinylpyrrolidone-density gradient are summarized in Table III. A remarkable finding is the reduced cholesterol/phospholipid ratio, particularly in the lipoproteins of the density 1.006 to 1.063 .

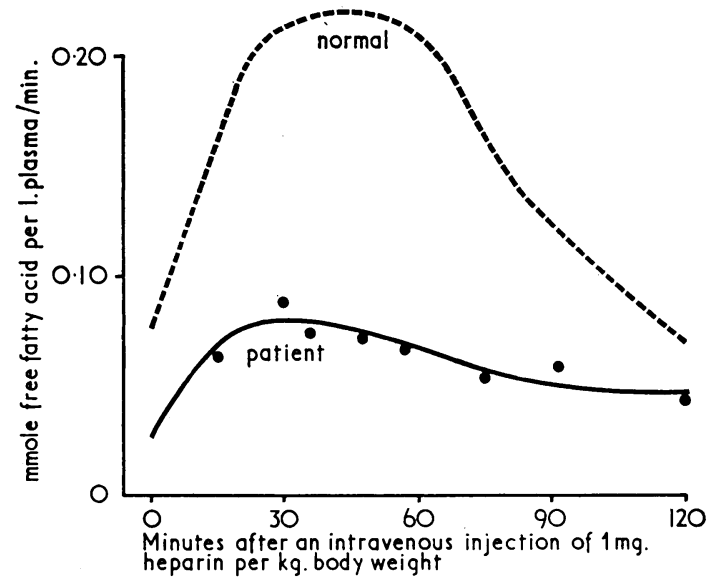

FIG. 2.-Appearance of lipoprotein lipase activity in blood stream of Case 1 and of normal man after heparin injection.

TABLE III.-Plasma Lipoproteins in Case 1

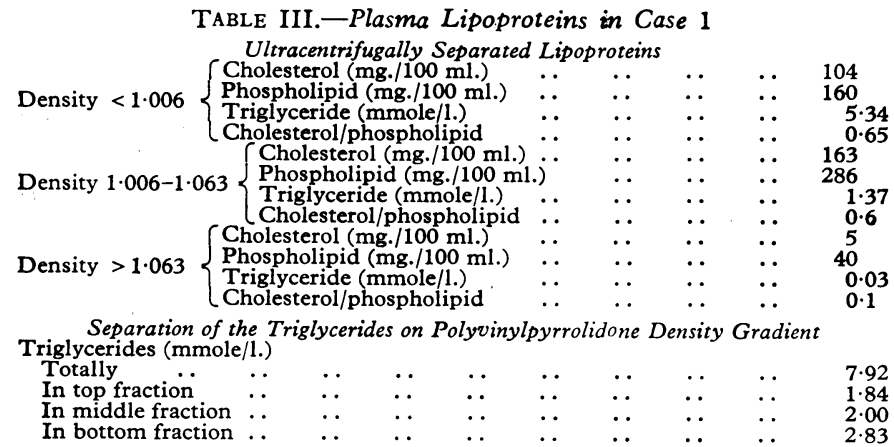

Haematological Examinations.-Table IV shows a moderate normochromic anaemia with a slight rise in reticulocytes and serum iron and a low haptoglobin. Some of the erythrocytes were in the form of target cells. The osmotic fragility was normal. The plasma concentrations of vitamin $\mathrm{B}_{12}$ and folic acid were normal. Bleeding and coagulation times were three minutes and two and a half minutes respectively. The bone marrow showed a proliferative picture in both erythropoiesis and myelopoiesis. There was a slight increase of the immature eosinophils. Thrombocytopoiesis was apparently normal. The number of reticulum cells was slightly increased. No foam cells could be seen. Half-life for ${ }^{51} \mathrm{Cr}$-labelled erythrocytes was found to be 17 days (normal 26-38 days). Surface scanning of ${ }^{81} \mathrm{Cr}$ over the heart, liver, spleen, and the sacrum and ilium showed an abnormally high activity over the spleen, which was about the same as over the heart during a 10-day period. There was a normal gradual fall in radioactivity over the heart, spleen, and liver. The uptake over the sacrum and ilium showed a slight increase during the period.
The most important haematological findings were thus moderate haemolysis with good compensatory increase in red cell production.

\section{TABLE IV.-Case 1. Laboratory Values in May 1968}

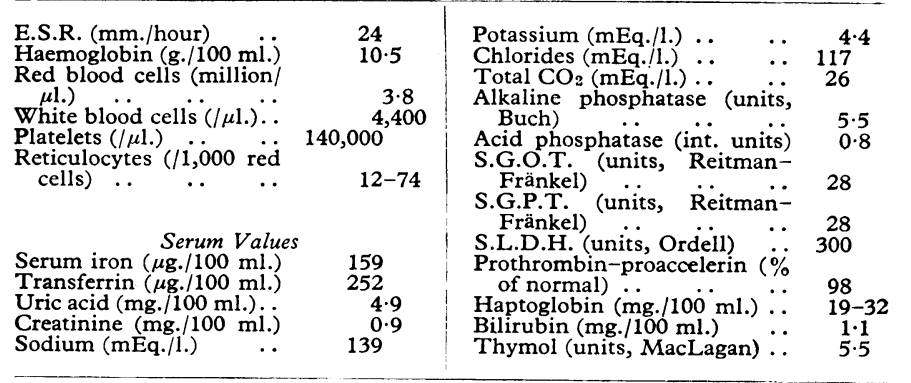

Total blood volume Erythrocyte volume Erythrocyte volum
Plasma volume

$$
\begin{aligned}
& 4,090 \mathrm{ml} \text {. (normal } 3,600-5,600 \mathrm{ml} \text { ) } \\
& 1,100 \mathrm{ml} \text { (normal } 1,200-2,700 \mathrm{ml} \text { ) } \\
& 2,900 \mathrm{ml} \text {. (normal } 1,900-3,400 \mathrm{ml} \text { ) }
\end{aligned}
$$

Lipid pattern of erythrocytes.-The results of the red cell lipid analysis showed a pattern which was similar to that previously described in L.C.A.T. deficiency (Gjone et al., 1968). The amount of cholesterol is about twice as much as normal and the phospholipid distribution shows relatively high lecithin and low phosphatidyl ethanolamine and sphingomyelin in all the cases.

Other Laboratory Findings._Laboratory values in May 1968 are given in Table IV. Serum iron was moderately increased and haptoglobin was low. Other values were within normal limits. Specific gravity of the urine was $1,008-1,014$. There was constant proteinuria up to $1.5 \mathrm{mg} . / \mathrm{ml}$., $80 \%$ of which was shown by electrophoresis to be albumin. A distinct peak could also be seen between the alpha 2- and beta-regions. Occasionally there was an increased amount of erythrocytes. No granulated casts were seen. Endogenous creatinine clearance was $87.7 \mathrm{ml} . / \mathrm{min}$. Serum proteins were electrophoretically normally distributed (total proteins $6.1 \mathrm{~g} . / 100 \mathrm{ml}$., albumin 3.8 g. $/ 100 \mathrm{ml}$.). Blood group was A Rh-positive. Vitamin A test showed normal fat absorption. Galactose-tolerance test and glucose tolerance curve after $1 \mathrm{~g}$. of glucose by mouth per $\mathrm{kg}$. body weight were normal. The antistreptolysin titre, according to the method of Hällén (1963), showed an extremely high value of 72,000 units. Reduction to 3,600 units after precipitation of the beta-lipoproteins with dextran sulphate showed its non-specific nature. Also the three Norwegian cases showed a definite non-specific rise in antistreptolysin titre values with this method $(72,000,30,000$, and 25,000 units, respectively), with marked reduction after dextran sulphate precipitation.

\section{Case 2}

This patient (III 17), was the brother of Case 1. He was born in 1924 and was known to have had proteinuria since 1941. He was admitted to hospital in 1941 and 1944 because of proteinuria, but he had no symptoms from this. In 1958 he was carefully examined before he was given a driving licence. He then had quite normal kidney function as tested by concentration test, intravenous pyelography, and endogenous clearance of creatinine. In 1958 corneal opacity was noted for the first time. The opacity affected the whole cornea, but was most pronounced in the periphery. In 1961 he was again admitted to hospital because of the proteinuria and slight haematuria. His haemoglobin level was then about $70 \%$, while the serum non-protein nitrogen was $61 \mathrm{mg} . / 100 \mathrm{ml}$. The spleen was palpated about $2 \mathrm{~cm}$. below the costal arch. The blood pressure was normal. There was slight gynaecomastia. No spider naevi were seen. Serum bilirubin was $0.3 \mathrm{mg} . / 100 \mathrm{ml}$. Examination of a liver biopsy showed small groups of cells, containing droplets of lipids. Lipaemic plasma was observed. Serum cholesterol was $137 \mathrm{mg} . / 100 \mathrm{ml}$. Without precipitation with dextran sulphate the antistreptolysin titre 
was $\geqslant 12,800$ units. In the autumn of 1964 he was admitted to hospital with advanced uraemia, from which he died in January 1965.

At necropsy a chronic diffuse glomerulonephritis was found. Histological examinations showed many similar features to that seen in the kidney needle biopsy from the Norwegian patient (A.R.) (Gjone and Norum, 1968a) but much more advanced, Further details will be published elsewhere (Oystese, Lindgren, and Hamnström, in preparation). Moderate atrophy was seen in the central parts of the liver lobuli. Advanced atheromatosis was noted in the abdominal aorta.

\section{Family Studies}

The family comes from a district in Western Sweden near the border of Norway, where the population is now small and stable. The family tree is shown in Fig. 3. Altogether 23 other members of the family were examined for total and free cholesterol and alpha-lipoprotein. The mother of the patients, all their siblings, and the son of Case 1, together with the daughter of Case 2, were also examined clinically, but no signs of eye or kidney disease were found. One brother (III 15) had raised non-specific antistreptolysin titre (14,000-1,000 units) but the L.C.A.T. activity was not decreased. Of special interest are two dead relatives. The patients' grandfather (I 4 ) had eye disease, diagnosed by an ophthalmologist as Egyptian ophthalmia it is known that trachoma when healing of ten causes corneal opacity). An uncle (II 11) died at the age of 43 from uraemia. Necropsy showed small fibrotic kidneys.

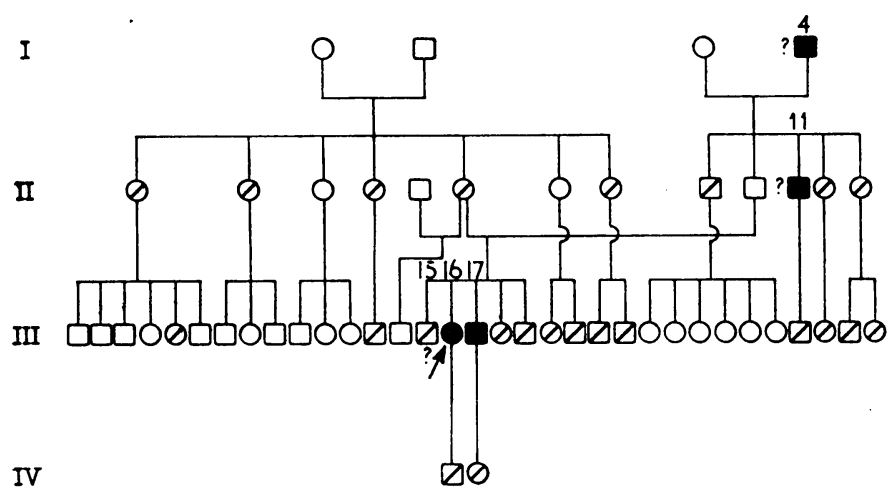

FIG. 3.-Family tree. Solid symbols are manifest cases. A line across the symbol indicates that the member has been examined.

\section{Discussion}

Our Case 1 and the Norwegian cases with L.C.A.T. deficiency have both clinical and biochemical similarities. All have corneal opacity, target cells, normochromic anaemia with a slight haemolytic compound, and proteinuria without renal insufficiency. The esterified part of the plasma cholesterol was definitely reduced, the concentration of lecithin was raised, and that of lysolecithin decreased. There was hypertriglyceridaemia, while the alpha-lipoprotein could hardly be detected. The pattern of the red cell lipids were similar. Deficiency of plasma L.C.A.T. was also clearly shown, though some L.C.A.T. activity was present in Case 1. Nevertheless there are also some differences between our patient and those reported previously. The level of the esterifled fraction of the cholesterol is greater than in the Norwegian cases $(27 \%$ against $3-10 \%)$. Moreover, the pattern of the fatty acids esterified with cholesterol is different, in this case a greater amount of linoleic acid and a lesser amount of the saturated fatty acids being present. This may be due to the small L.C.A.T. activity in plasma of Case 1.

Case 2 had also suffered from the same disease. He had the corneal clouding, proteinuria of many years' duration without renal insufficiency, and lipaemic serum. It seems very probable that he died of a renal disease different from an acquired glomerulonephritis.
The extreme lowering of the alpha-lipoprotein in Case 1 is of almost the same degree as in familial high-density lipoprotein deficiency (Tangier disease). Corneal clouding (Hoffman and Fredrickson, 1965) and proteinuria (Kocen et al., 1967) are reported in some of the adults with this disease. Case 1, however, lacks the particular features of Tangier disease-namely hypocholesterolaemia and the heavy infiltrations of cholesterol esters in the lymphoid tissues, particularly the tonsils.

The extreme rise in the non-specific antistreptolysin titre is noteworthy. The highest values and the greatest reduction after precipitation by dextran sulphate occur in various nonhaemolytic types of jaundice (Winblad, 1966) and most patients with non-icteric hypercholesterolaemia of different types have normal levels of non-specific antistreptolysin titre. The exact origin for a non-specific antistreptolysin titre is still unknown, but there is probably some factor in those lipoproteins that are precipitated by polyanions. The very high values, typical of L.C.A.T. deficiency, would seem an excellent starting point for studying this problem. An earlier observation of low lysolecithin with simultaneous increase in leoithin in obstructive jaundice is of special interest (Gjone and Orning, 1966).

Glomset has suggested that the acyltransferase reaction has a role in the transport of cholesterol from the tissues to the liver and influences membrane homoeostasis (Glomset, 1968). Support for this theory is the abnormal lipid pattern of the red cells at the familial plasma L.C.A.T. deficiency (Gjone et al., 1968). The discovery of the disease can also increase our knowledge of the synthesis and metabolism of the lipoproteins, both of which have also been helped by studies on two other deficiency states (a beta-lipoproteinaemia and Tangier disease).

This work was supported by grants from the County Council of Värmland, Gustaf and Maja Johansson's Fond, Sweden, and Anders Jahre's Fond, Norway.

\section{REFERENCES}

Babson, A. L., Shapiro, P. O., and Phillips, G. E. (1962). Clinica Chimica Acta, 7, 800.

Boberg, J., and Carlson, L. A. (1964). Clinica Chimica Acta, 10, 420. Bragdon, J. H., Havel, R. J., and Boyle, E. (1956). Fournal of Laboratory and Clinical Medicine, 48, 36.

Burstein, M., and Samaille, J. (1960). Clinica Chimica Acta, 5, 609.

Carlson, L. A. (1960). Acta Medica Scandinavica, 167, 1.

Carr, J. J., and Drekter, I. J. (1956). Clinical Chemistry, 2, 353.

Gjone, E., and Bergaust, B. (1969). Acta Ophthalmologica. In press.

Gjone, E., and Norum, K. R. (1968a). Acta Medica Scandinavica, 183, 107.

Gione, E., and Norum, K. R. (1968b). Nordisk Medicin, 80, 878.

Gjone, E., and Orning, O. M. (1966). Scandinavian fournal of Clinical and Laboratory Investigation, 18, 209.

Gjone, E., Torsvik, H., and Norum, K. R. (1968). Scandinavian fournal of Clinical and Laboratory Investigation, 21, 327.

Glomset, J. A. (1968). Fournal of Lipid Research, 9, 155.

Glomset, J. A., and Wright, J. L. (1964). Biochimica et Biophysica Acta, 89, 266.

Hallberg, D. (1964). Acta Physiologica Scandinavica, 62, 407.

Hällén, J. (1963). Acta Pathologica et Microbiologica Scandinavica, 57, 301 .

Hamnström, B. (1969). Acta Medica Scandinavica. In press.

Hoffman, H. N., and Frederickson, D. S. (1965). American fournal of Medicine, 39, 582.

Jencks, W. P., and Durrum, E. L. (1955). Fournal of Clinical Investigation, 34, 1437.

Kocen, R. S., Lloyd, J. K., Lascelles, P. T., Fosbrooke, A. S., and Williams, D. (1967). Lancet, 1, 1341.

Laurell, S. (1966). Scandinavian fournal of Clinical and Laboratory Investigation, 18, 668.

Norum, K. R., and Gjone, E. (1967a). Biochimica et Biophysica Acta, 144, 698 .

Norum, K. R., and Gjone, E. (1967b). Scandinavian fournal of Clinical and Laboratory Investigation, 20, 231.

Pié, A., and Giner, A. (1966). Nature, 212, 402.

Schrade, W., Boehle, E., Biegler, R., and Harmuth, E. (1963). Lancet, $1,285$.

Sonnino, F. R., and Gazzaniga, P. P. (1961). Clinica Chimica Acta, 6, 295.

Torsvik, H., Gjone, E., and Norum, K. R. (1968). Acta Medica Scandinavica, 183, 387 .

Winblad, S. (1966). Acta Pathologica et Microbiologica Scandinavica, 66, 93. 